\title{
Comparison on Labor Dispatching between China and Western Countries and Countermeasure Exploration
}

\author{
Qiang Chen ${ }^{1}$, Huiying Luo $^{2}$ \\ ${ }^{1}$ School of Business Administration, Chongqing University of Science and Technology, Chongqing, \\ 400042, China \\ ${ }^{2}$ School of Economics and Business Administration, Chongqing University, Chongqing, 401331, \\ China
}

Keywords: Labor dispatching; employment plan; countermeasures

\begin{abstract}
In recent years, China has an extremely rapid development in labor dispatching, but the dispute never stops; as for labor dispatching, we can only standardize its development rather than give up eating for fear of choking. On the basis of analysis on development history and current status of domestic and foreign labor dispatching, this paper specifically analyzes main problems existing in domestic labor dispatching, and combines with beneficial experience of western developed countries to propose the measures and suggestions for perfecting domestic labor dispatching for the hope of standardizing Chinese labor dispatching.
\end{abstract}

\section{Overview of labor dispatching}

Labor dispatching is also called labor force dispatching, and it is a kind of specific employment way in which the demand unit and the dispatching unit sign a dispatching agreement via negotiation, the dispatching unit and the dispatched employee sign a labor contract, and then the dispatching unit dispatches such employee to the demand unit to make such employee work and accept commanding and supervision of the demand unit in the demand unit's work place so as to complete combination of labor force and production materials. After the demand unit relieves the work relation with laborer, it can return the laborer to the dispatching unit to wait for employment. At this time, the laborer is not out of work, but still belongs to the employee of dispatching unit and will be then dispatched to another demand unit. After a laborer relieves the work relation with a demand unit, the dispatching unit will provide such laborer with basic cost of living allowances before he is dispatched to another unit. (As shown in Figure 1: operation mechanism of labor dispatching)

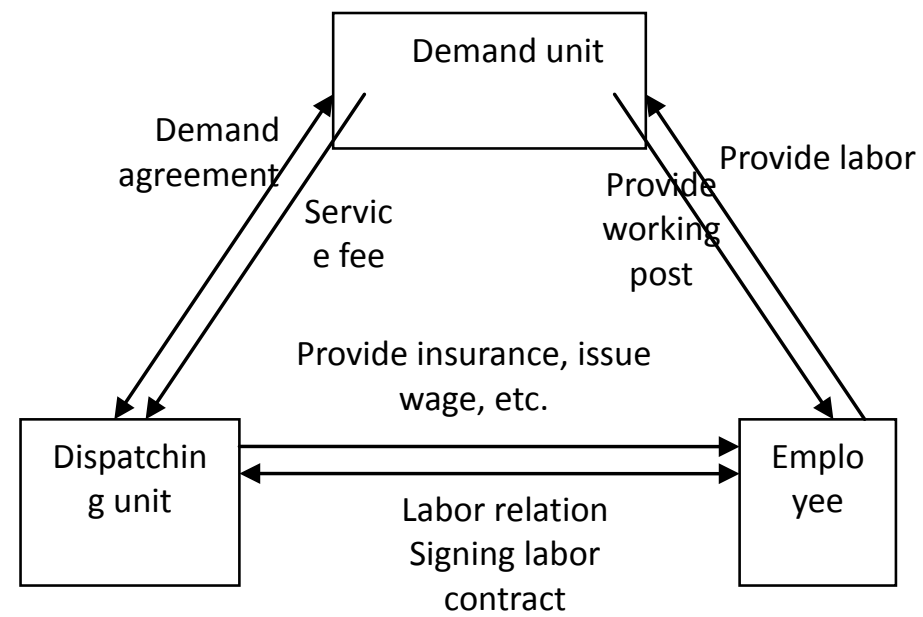

Figure 1: operation mechanism of labor dispatching

The legal relation of labor dispatching involves 3 parties: dispatching unit, demand unit, and dispatched employee. The dispatching institution is an institution which recruits laborers and dispatches laborers to employing unit; the demand unit is a unit which accepts the employment of 
labor dispatching form.

\section{Foreign development situation of labor dispatching and employment regulations}

\section{(I) Development history of labor dispatching}

As a kind of employment system in which the employment and use are separated, it originates from the United States, and grows up in Europe and Japan; currently, it has been widely applied in many countries.

In the United States in 1920, Samuel Workman initiated the idea of "rented help"; he employed a batch of married women to handle inventory work at night; later, he trained women to operate calculators and provided current enterprise with temporary or short-term demand. At that time, the similar contract work gradually evolved as labor dispatching service industry. In 1940-1960, the labor dispatching was gradually popular in the United States and Europe.

In Europe, from the later 1940s to the beginning of 1950s, the working condition similar to labor dispatching had existed in Belgium, France, the United Kingdom, the Netherlands, and Norway. In 1980s, due to economic recession, in order to reduce the cost, the enterprises' enthusiasm in seeking for "labor dispatching" and other flexible way of employment was enhanced, and the enterprises paid more and more attention to work schedule of partial labor-hour laborers, temporary employees, and labor outsourcing. In this period, the labor dispatching in Europe and the United States had a rapid development. In Asia, the labor dispatching early appeared in Japan. In 1967, the Japan's economic growth rate was more than $10 \%$, thus there was strong demand of talents; furthermore, under the influence of capital liberalization, large quantity of foreign capital entered into Japan. At that time, American enterprise "Manpower" introduced labor dispatching into Japan in 1966; in 1967, it officially established "Manpower Japan" company to take foreign companies as object for labor dispatching. Later, Japan's labor dispatching started its development; in 1986, Labor Dispatching law was published, which accelerated the development.

\section{(II) Employment regulations for labor dispatching of western developed countries}

1. Restricting labor dispatching within the scope of "temporary employment"

The developed countries such as European Union, the United States, and Japan all restrict labor dispatching within the scope of "temporary employment" and determine it as a supplementary form for standard employment; it still plays a secondary role and accounts for a small proportion, and it only exists as a supplementary form of standard employment.

2. Paying attention to protecting the dispatched laborers' legal rights and interests

In terms of law, the western developed countries all require that the labor dispatching unit and employment unit shall jointly bear "employer's liability" stipulated in law, that is, both parties shall jointly share all legal duties that the employer shall bear for laborers under the standard labor relationship.

3. Standardizing temporary employment and part-time employment through labor dispatching

Through signing long-term or permanent labor contract with labor dispatching unit, the laborers who engage in temporary employment and hourly employment become its formal fixed employees and then they are dispatched to work in the employment unit which needs temporary workers and hourly workers. In this way, those laborers who engage in temporary and hourly employment are placed under the legal protection of standard labor relationship, and they can enjoy laborers' all legal rights and interests as formal fixed employees. Furthermore, under the condition that they temporarily have no "temporary employment", the labor dispatching unit will issue "wait-for-employment wage" on one hand, and seek for new "temporary employment" for them on the other hand.

4. Adopting more "regular employment", and implementing stricter management on "registered employment”

Through enhancing dispatching unit's final employer liability, the "regular employment" labor dispatching forces the dispatching unit to actively enhance contact and supervision on employment unit, and actively strive for interests for laborers. Except for "regular employment", there also exists "registered employment" labor dispatching, that is, the dispatched laborer is not formal fixed staff 
of dispatching unit, but has "been registered and recorded" in dispatching unit. When the employment unit has temporary employment demand, the dispatching unit can sign a labor contract with the laborer according to employment time and then dispatch him to work in employment unit. In the wait-for-employment period between two labor dispatching, there is no labor relationship between dispatching unit and "registered" laborer, thus it is unnecessary for dispatching unit to bear any risk for the laborer.

5. Paying attention to professional service, training, and management

As for foreign labor dispatching institutions, the most standard operation is "talent dispatching"; most of those staffs are regularly employed staffs of labor dispatching institutions and dispatched for long time. Those labor dispatching institutions pay much attention to service concept, and adopt professional way for operation. In order to improve service quality, most of their externally dispatched employees have accepted professional skill training, and some even have accepted work shift training for convenience of improving externally-dispatched staffs' comprehensive business quality and ability.

\section{Development situation of labor dispatching in China and main existing problems}

\section{(I) Development origin of labor dispatching in China}

In 1979, Beijing Foreign Enterprise Human Resource Service Company dispatched Chinese employees to the representative office of one Japanese company in China, which marked that the labor dispatching stepped into China. With stationing of large quantity of foreign enterprises and by virtue of advantage of labor dispatching, the labor dispatching is popular among enterprises in short time. Currently, Chinese labor market continues to keep a condition of oversupply, which provides rich soil for development of labor dispatching companies.

\section{(II) Development status of labor dispatching in China}

Currently, the labor economy including labor dispatching is a new business opportunity in China, and the development status can be generalized as rapid development, great potential, disorderly competition, and insufficient standards. According to survey situation, Chinese labor dispatching status is shown as below.

The industries which adopt labor dispatching work arrangement are mainly service industry, manufacturing industry, and construction industry, such as telecommunications, banks, restaurant, hospital, postal service, housekeeping, electric power, and railway transportation, as well as some departments of construction industry and manufacturing industry. The labor dispatching is especially popular among foreign-funded enterprises, advantage enterprises and large stated-owned enterprises.

\section{(III) Main problems existing in Chinese labor dispatching}

1. Difficult realization of equal pay for equal work

In reality, the demand unit always tries its best to reduce remuneration level of dispatched laborers to reduce employment level of unit. In labor dispatching, the differential treatment and equal pay for equal work commonly exist, which even becomes the original idea of some enterprises to select the labor dispatching way, that is, reducing employment cost. Furthermore, the rules related to equal pay for equal work of dispatched laborers in Labor Contract Law lack of specific operation standard, thus it is also difficult to realize those rules.

2. Serious abuse of labor dispatching

Due to excessively rapid development of labor dispatching, the abuse of labor dispatching is shown continuously. Under most conditions, the cost is the only factor to be considered in using labor dispatching; therefore, as long as it is able to reduce the cost, avoid responsibilities, and alleviate risk, the labor dispatching can be applied at any post. The act of evading legal rules or responsibilities becomes a practice that most large enterprises take.

3. Poor labor stability of dispatched employees

Due to difference in social benefits and identity discrimination, wide dispatched employees have a low loyalty and sense of belonging, and a high demission rate.

4. Weak overall strength of labor dispatching institutions 
The threshold of "registered capital of not less than RMB 500,000 yuan" is low, which results in a situation that the operation of partial labor dispatching institutions is similar to common small intermediary agents with several personnel and easy office environment; once an accident happens, they will disappear irresponsibly. Meanwhile, the labor dispatching employment personnel have a low quality, and the talents familiar with human resource and labor dispatching are insufficient.

\section{(IV) Difference in domestic and foreign labor dispatching}

Through comparison, there mainly exist three aspects of gap between foreign standard operation and Chinese labor dispatching:

Firstly, it is different reason for laborers to select dispatching work. Chinese dispatched employees' employment ability and the ability to obtain work information are relatively poor; under condition of lacking of formal work opportunity, most of them passively select to participate in labor dispatching.

Secondly, the dispatched employees engage in different levels of occupation. Currently, there are mainly two types of work of foreign labor dispatching: one is basic-level work without need in any professional skill, and the other is work in need of highly professional skill; these two types of work account for about $50 \%$ respectively. However, in China, more than $80 \%$ of dispatched employees all engage in basic-level work without need in professional skills, and those works have strong repetition and intensity, which shows that China has an unreasonable distribution of type of work of labor dispatching.

Thirdly, it is different legislation process. Currently, foreign countries have issued special laws of labor dispatching in succession; however, China has no special laws and regulations related to labor dispatching.

\section{Measures and suggestions for perfecting Chinese labor dispatching}

\section{(I) To perfect labor dispatching guarantee system}

As a kind of market configuration way of human resources, many policies, systems, and regulations related to labor dispatching are not perfect in real management.

1. To standardize legality of labor dispatching from perspective of laws and regulations

In recent few years, some administrative management rules stipulating labor dispatching activities have appeared in various places, which makes active efforts for standardized development of labor dispatching. However, in terms of national level, there is no official legislation of labor dispatching and uniform law and regulation system on a national scale. Therefore, on the basis of related survey, it is required to formulate special labor dispatching law with reference to domestic and foreign advanced experience so as to ensure equal pay for equal work of dispatched employees and formal employees, ensure fairness, and also guarantee their psychological balance and stability.

2. To perfect comprehensiveness of labor dispatching management system from perspective of matching rules

Except for stricter stipulations on registered capital of labor dispatching unit, it is required to restrict the labor dispatching employment personnel's qualification and quality, and establish a perfect management system. As for establishment threshold and procedure of labor dispatching institutions, except for conditions stipulated in law, it is also required to pass review and approval of relevant labor administrative departments for convenience of enhancing the government monitoring on labor dispatching institutions and labor dispatching operation behaviors to ensure healthy and smooth development of labor dispatching.

3. To exert the public benefit of government institutions from perspective of government functions

In a word, the labor dispatching aims at expanding employment scale, solving re-employment problems of laid-off workers, and organizing peasant workers' orderly employment. All of those functions belong to governmental public service functions. It is suggested that the government shall establish public-benefit dispatching institutions; on one hand, it can provide employment units with corresponding labor dispatching service as well as corresponding preference and support policies; on the other hand, it can protect the dispatched labor personnel's legal rights and interests, and 
establish and maintain stable and harmonious labor relation situation.

\section{(II) To strictly restrict dispatching of working post}

It is stipulated in Article 66 of Labor Contract Law that the labor dispatching is generally carried out in temporary, auxiliary or alternative working post. This article actually regulates labor force dispatching market to certain degree; however, the specific "temporary", "auxiliary", or "alternative" work can't be divided in details. There are at least thousands of common types of work, but it is impossible that the rules will be made for those types one by one. Therefore, there shall be more scientific way as basis to divide dispatching working posts in the future.

\section{(III) To expand labor supervision}

The labor security supervision objects of labor dispatching include dispatching company, and the unit of using dispatched personnel (including family). For example, in view of wide housekeeping service points and insufficient current supervision on labor protection, it is able to consider letting management personnel and supervision personnel of dispatching company undertake partial supervision function through carrying out training of labor laws and policies on them and requiring them to take post with certificate so as to maintain laborers' legal rights and interests. In this way, it is able to effectively protect laborers' interests; however, the supervision on labor dispatching still remains to be perfected.

(IV) To further deepen the reform of state-owned enterprises, and gradually eliminate the phenomenon of "double-track" employment"

The above suggestions are mainly proposed based on legislation and law enforcement. However, the system perfect is a systematic project, so is the equal pay for equal work under labor dispatching. Except for legal standards, we shall pay more attention to problems caused by systematic conflict. Nowadays, the "double-track employment" in the reform process of state-owned enterprises is one of fundamental reasons which result in unequal pay for equal work under labor dispatching. In a sense, to further deepen the reform of state-owned enterprises and gradually cancel "double-track employment" is of important function and significance for perfection of Chinese labor dispatching law system and realization of “equal pay for equal work” under labor dispatching.

\section{Bibliography}

[1] Guan Yingzhi: Study on Development of Chinese Labor Dispatching Service [D], China University of Geosciences, 2009.

[2] Wang Xin: Legal Thoughts on Labor Dispatching [D], Guangdong University of Foreign Studies Law School, 2009.

[3] Cui Ling: Study on Legislation Problems of Chinese Labor Dispatching [D], Yantai University, 2009.

[4] Yan Liming, Yu Dehou: Analysis on Current Situation of Labor Dispatching and Coping Strategies [J], China Trial News Monthly, 2009, 67:95-97.

[5] Li Shangyong: Employment Regulations on Labor Dispatching in Developed Countries [J], China Labor, 2009, 11:29-32.

[6] Yang Pengfei: Analysis on Abuse of Labor Dispatching in State-owned Enterprises [J], Shanghai Enterprise, 2011, 8:60-61.

[7] Ye Jing: Problems Existing in China's Labor Dispatching and Countermeasures [J], People's Tribune Academic Pioneer, 2011, 4.

[7] Huang Qianming: Discussion on Abuse of Labor Dispatching [J], The Merchandise and Quality, 2011, 9:122-122.

[8] Wang Dan: Analysis on Current Situation and Development Trend of Domestic and Foreign Labor Dispatching [J], 2011, 33: 187-188. 